\title{
Corneal endothelial specular microscopy following deep lamellar keratoplasty with lyophilised tissue
}

\begin{abstract}
Purpose To assess the corneal endothelial cell density following deep lamellar keratoplasty (DLK) carried out by air dissection and with the transplantation of lyophilised tissue. Method Contact endothelial specular microscopy was carried out on a series of patients who had undergone DLK with a minimum of 1 year post-operative follow-up. Results Twenty eyes of 18 patients were examined at follow-up times ranging from 1 to 8 years post-operatively (mean 3 years). Indications for surgery were: keratoconus $(n=12)$, herpes simplex virus (HSV) keratitis $(n=1)$, herpes zoster ophthalmicus (HZO) keratitis $(n=1)$, lipid keratopathy $(n=2)$, lattice dystrophy $(n=1)$ and corneal scarring $(n=3)$. Overall, mean post-operative cell density was 2417 cells $/ \mathrm{mm}^{2}$ (range $928-3656$ cells $/ \mathrm{mm}^{2}$ ). In eyes with pathological conditions not likely to have affected the endothelial cell density, such as keratoconus or lattice degeneration, the mean cell density was 2837 cells $/ \mathrm{mm}^{2}$ (range 1030-3656 cells $/ \mathrm{mm}^{2}$ ).

Conclusions In patients undergoing DLK for conditions such as keratoconus the postoperative cell density was at a normal level in the majority of cases. Cell loss through this surgical intervention thus appears generally to be small. The prospect for long-term survival of these grafts is good.
\end{abstract}

Key words Corneal endothelium, Keratoconus, Lamellar keratoplasty, Lyophilised corneal tissue, Penetrating keratoplasty

Whilst there have been a number of reports of studies of endothelial cell density following penetrating keratoplasty, little has been published about the endothelium following lamellar keratoplasty. A recent paper by Sugita and Kondo ${ }^{1}$ describes their method of deep lamellar keratoplasty (DLK) for the treatment of corneal scarring. In their series the mean postoperative endothelial cell density measured at
E. MORRIS, J.F. KIRWAN, S. SUJATHA,

C.K. ROSTRON
1 month was 2225 cells $/ \mathrm{mm}^{2}$ and at 2 years was 1937 cells $/ \mathrm{mm}^{2}$.

With regard to penetrating keratoplasty, studies have shown considerable progressive decline in post-operative endothelial cell density. A 4 year follow-up of 12 routine penetrating grafts without complications showed that the endothelial cell count underwent an exponential decline, and that the cell density was typically halved within about 4 years. $^{2}$ In another recent report of 77 patients followed for 10 years post-operatively it was found that the mean endothelial cell density at 10 years was $976 \pm 484$ cells $/ \mathrm{mm}^{2}$, and that in the period between 5 and 10 years after penetrating keratoplasty, corneal grafts lose central endothelial cells at the rate of $3.8 \%$ per year, which is 6 times greater that the rate associated with normal ageing. ${ }^{3}$ In another long-term study, the mean cell density of 100 grafts with post-operative intervals of 9-33 years was 684 cells $/ \mathrm{mm}^{2}$. In the longest study so far, 49 surviving grafts from the aforementioned series were reviewed 5 years later. During those 5 years there was a continued decline in the number of cells at a rate of 15 cells $/ \mathrm{mm}^{2}$ per year, and obviously at this level of endothelial depletion there were a number of graft failures due to endothelial decompensation. ${ }^{5}$ These reports are a cause of concern for the long-term survival of penetrating grafts.

Statistics from the United Kingdom Transplant Support Service Authority (UKTSSA) show that $44 \%$ of corneal graft recipients are aged between 18 and 60 years, ${ }^{6}$ and the required graft survival time in this group might be from 30 to 70 years. Patients in the younger age groups requiring keratoplasty have a higher proportion of pathology where endothelial function is good, such as

keratoconus or corneal dystrophy, and therefore lamellar keratoplasty could offer these patients a better prospect of long-term graft survival. At present less than $5 \%$ of grafts carried out in the UK are lamellar grafts. ${ }^{6}$
E. Morris

J.F. Kirwan

S. Sujatha

C.K. Rostron

St George's Hospital London, UK

Mr Chad K. Rostron, FRCOphth Department of Ophthalmology St George's Hospital Blackshaw Road London SW17 0QT, UK

Tel: +44 (0)181725 2325

Fax: +44 (0)181725 3026

This work was supported by Keratec (registered charity no. 803386 ) 
Whilst preservation of the patient's own endothelium is the main advantage of DLK, there is little known about the damage to the host endothelial cells incurred by different keratoplasty techniques. In this hospital patients are treated by lamellar rather than penetrating keratoplasty where they have corneal pathology associated with a functional endothelial cell density as shown by a lack of corneal oedema pre-operatively. Typically the patient's Descemet's membrane is cleaved from the deep stroma by air-, hydro- and visco-dissection (Fig. 1). To assess the degree of damage such surgical manoeuvres induce in the host endothelium we carried out a survey by specular microscopy of the corneal endothelium of patients who had undergone DLK.
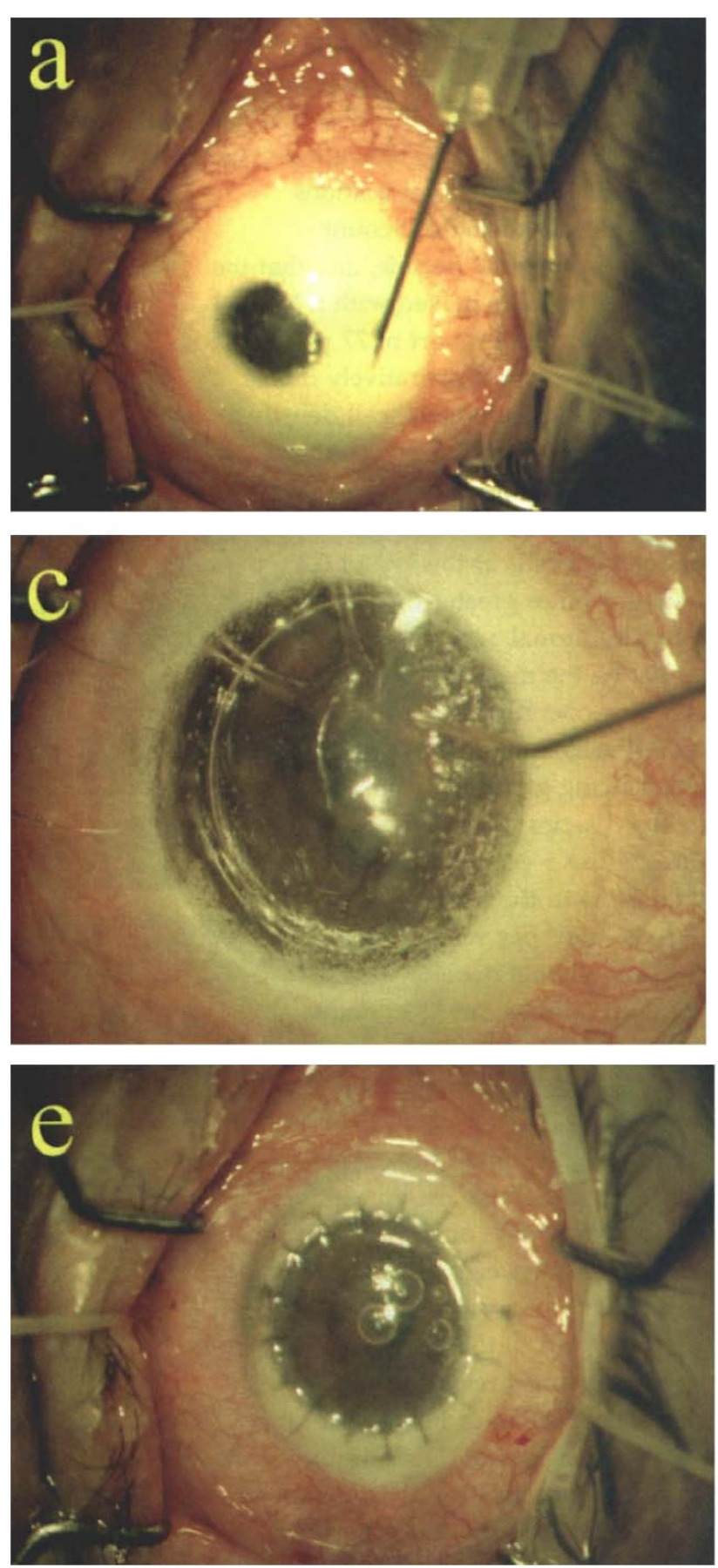

Fig. 1. Keratoconus treated by deep lamellar keratoplasty (DLK) on air. (a) Air injection. (b) Lamellar resection. (c) Hydrodissection. Note the spherical air bubble in pre-Descemet's plane, and other bubbles in the anterior chamber. (d) Excision of residual deep stroma whilst Descemet's membrane is held clear by viscoelastic. (e) Completed surgery with lyophilised lenticule. (f) Post-operative view.

\section{Materials and method}

Patients attending for routine follow-up for DLK were enrolled into the study. We examined a series of 20 DLKs in 18 patients who had undergone the operation for a variety of indications. Only post-operative imaging of the endothelium was possible in this cohort of patients, since we did not have access to a specular microscope at the time of their pre-operative assessment. The endothelium was examined using a Keeler-Konan 'Pocklington' widefield contact specular microscope. Several photographs of the central endothelial area were taken, and the endothelial cell density was assessed by a variable frame analysis, where cells were counted
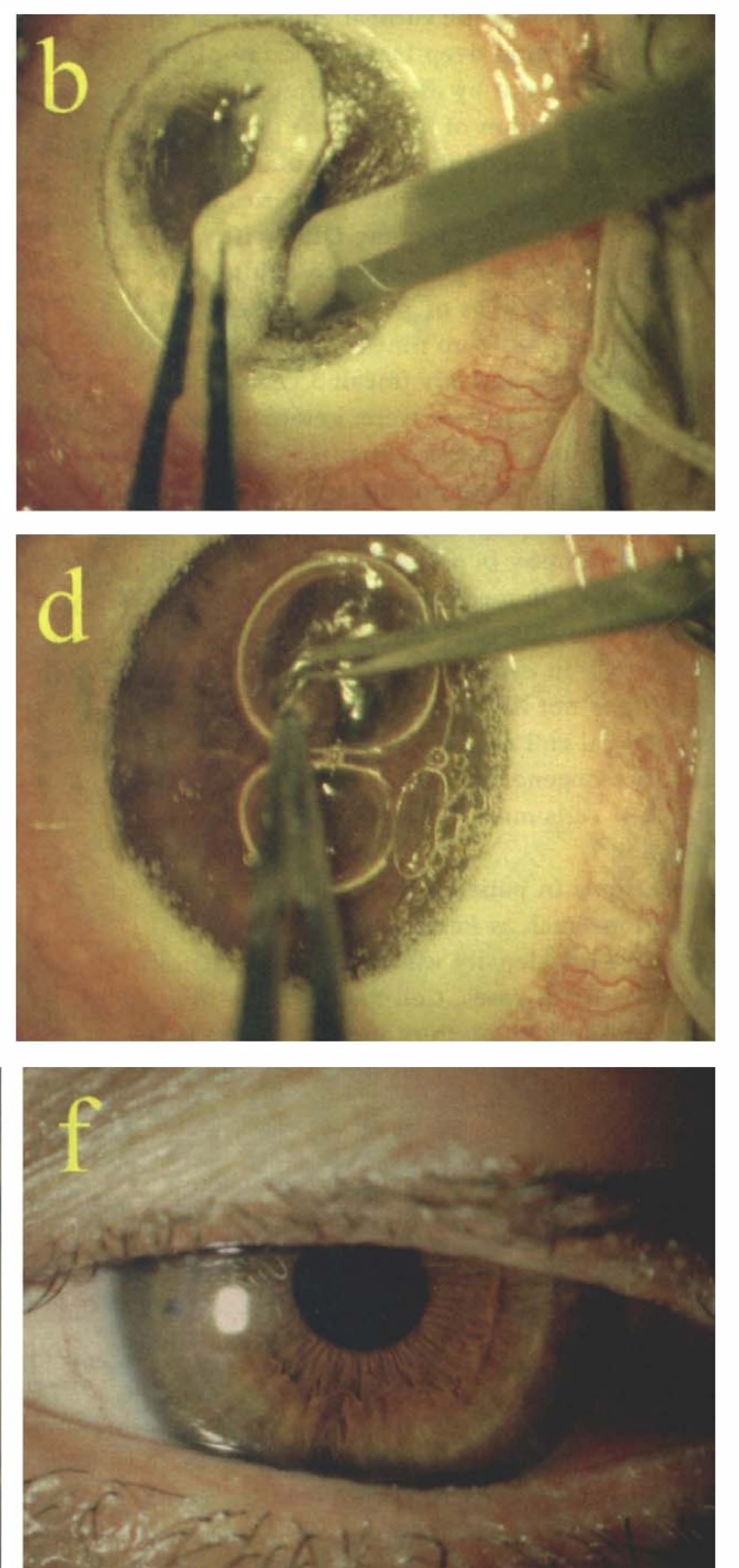


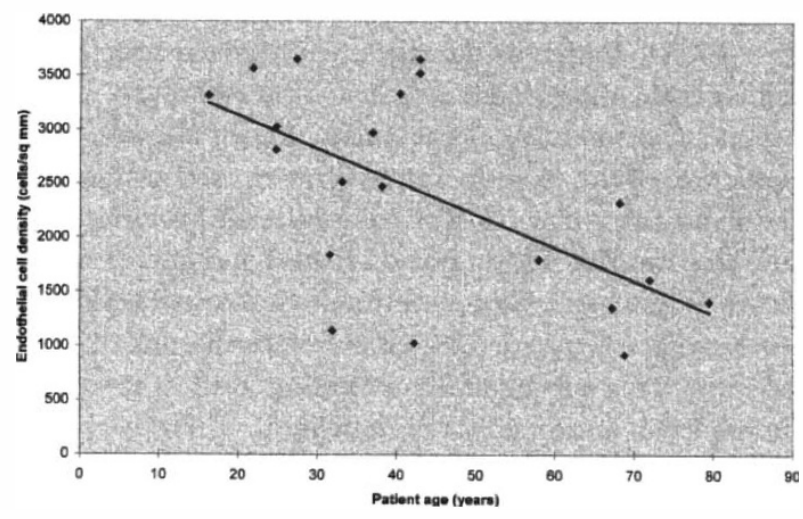

Fig. 2. Corneal endothelial cell density following DLK. Cell density is plotted against patient age.

manually on black and white prints and the area of cells was measured using a digitising tablet and NIH image software.

In 4 patients a comparison was made between cell density of the endothelium in their non-operated eye and density in the eye that had undergone DLK. In 4 other patients who had undergone DLK in one eye and penetrating keratoplasty $(\mathrm{PK})$ in the contralateral eye, the endothelial cell densities of the two eyes were also compared. All patients in the series were assessed at a minimum of 1 year post-operatively.

\section{Results}

The mean age of the patients was 43 years (range 16-79 years), and the mean follow-up time was 3 years (range 1-8 years). Indications for surgery were: keratoconus $(n=12)$, herpes simplex virus (HSV) keratitis $(n=1)$, herpes zoster ophthalmicus (HZO) keratitis $(n=1)$, lipid keratopathy $(n=2)$, lattice dystrophy $(n=1)$ and corneal scarring $(n=3)$.

Overall the mean post-operative cell density was 2417 cells $/ \mathrm{mm}^{2}$ (range $928-3656$ cells $/ \mathrm{mm}^{2}$ ), and there was a general downward trend with increasing patient age (Fig. 2).

Lower cell counts, of a mean of 1520 cells $/ \mathrm{mm}^{2}$, were found in eyes with underlying pathology potentially affecting the endothelium, such as lipid keratopathy, $\mathrm{HZO}$ and HSV keratitis, or following previous surgery such as cataract extraction with intraocular lens

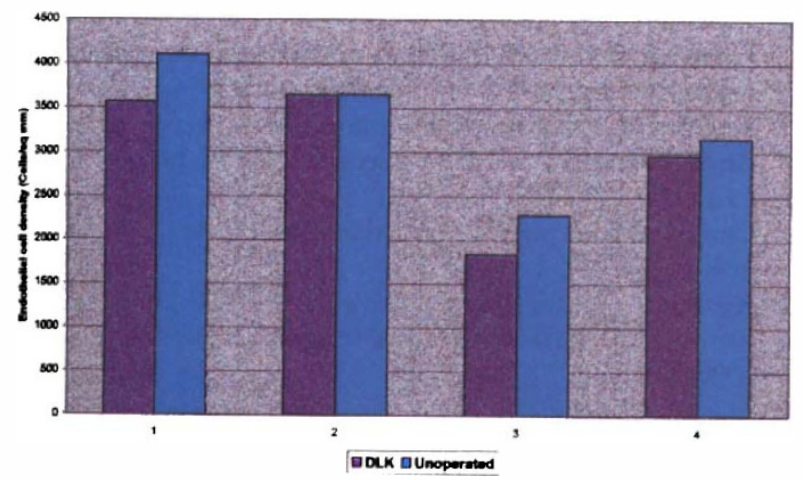

Fig. 3. Endothelial cell density following DLK compared with density in the contralateral unoperated eye.

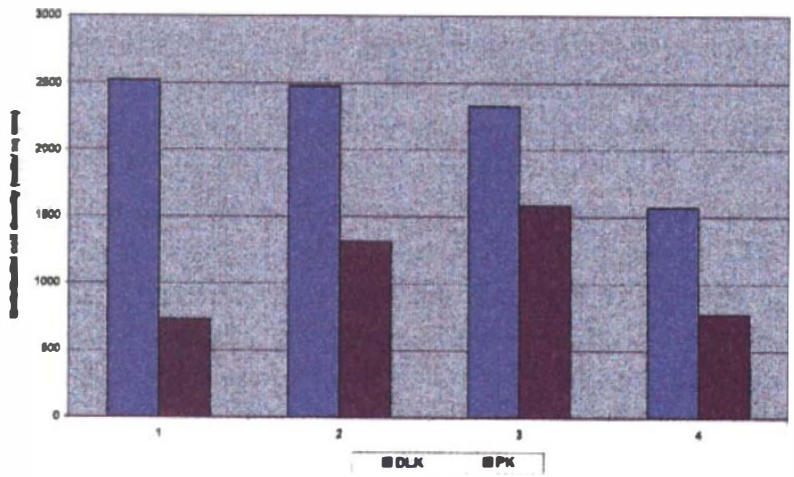

Fig. 4. Endothelial cell density following DLK in one eye compared with density following penetrating keratoplasty in the contralateral eye.

implantation $(n=7)$. The mean cell density in eyes with pathology not affecting endothelium, such as keratoconus or lattice degeneration, was 2837 cells $/ \mathrm{mm}^{2}$ $(n=13)$.

In the 4 patients where the comparison was made between the cell density of the endothelium in the nonoperated eye and the DLK eye, the cell counts in the operated eyes were on average $10 \%$ lower than in the unoperated eye (range 0.25-20\%) (Fig. 3).

In the 4 patients who had undergone DLK in one eye and PK in the other, the endothelial cell densities following PK were significantly lower than those after DLK, with the mean difference of $50 \%$ (range 32-71\%) (Fig. 4). The follow-up times, diagnoses and cell counts for these patients are shown in Table 1.

\section{Discussion}

Overall the cell counts in this series of patients undergoing DLK were within the normal range. The regression line shown in the scatter plot (Fig. 2) shows a gradual reduction in cell density with increasing patient age, and it is recognised that this is the general trend in normal corneas. ${ }^{7}$ Four patients $(20 \%)$ had cell counts of less than 1500 cells $/ \mathrm{mm}^{2}$, but 3 of these had suffered from inflammatory corneal pathology which would have been likely to cause pre-operative endothelial depletion. In such cases of corneal scarring it is not possible to obtain a pre-operative endothelial specular view, and so it is only in cases of clear corneal pathology that a

Table 1. Comparison of endothelial cell counts in patients with deep lamellar keratoplasty (DLK) in one eye and penetrating keratoplasty $(P K)$ in the contralateral eye

\begin{tabular}{lllcc}
\hline $\begin{array}{l}\text { Patient } \\
\text { no. }\end{array}$ & Diagnosis & $\begin{array}{c}\text { Graft } \\
\text { type }\end{array}$ & $\begin{array}{c}\text { Follow-up } \\
\text { time } \\
\text { (years) }\end{array}$ & $\begin{array}{c}\text { Cell } \\
\text { density } \\
\text { (cells } / \mathrm{mm}^{2} \text { ) }\end{array}$ \\
\hline 1 & Keratoconus & DLK & 5.6 & 2519 \\
1 & Keratoconus & PK & 12.7 & 733 \\
2 & Keratoconus & DLK & 2.3 & 2476 \\
2 & Keratoconus & PK & 3.4 & 1315 \\
3 & Corneal scarring & DLK & 3.2 & 2328 \\
3 & Corneal scarring & PK & 4.6 & 1583 \\
4 & Corneal scarring & DLK & 5.0 & 1570 \\
4 & Corneal scarring & PK & 5.7 & 773 \\
\hline
\end{tabular}


prospective comparative study of surgically induced cell loss could be performed. Although these patients had relatively low cell densities, the nature of their corneal pathology would have put them at high risk of rejection if they had undergone PK, so the decision to perform DLK would still seem to be justified in the retrospective knowledge of their post-operative cell densities.

However, in cases where we had the opportunity to compare the cell densities in the operated eye and the contralateral unoperated eye (Fig. 3), by assuming that the pre-operative cell densities were similar in the two eyes we were able to obtain an estimate of surgically induced cell loss. This ranged from $0.25 \%$ to $20 \%$ with a mean difference of $10 \%$, which compares well with the cell loss induced by other keratorefractive procedures. ${ }^{8}$

In the comparison of the subgroup of patients who had DLK in one eye and PK in the contralateral eye the cell counts were considerably lower in the PK eyes (Fig. 4, Table 1). The follow-up times for the PK eyes were, however, longer than for the DLK eyes. One would thus expect the cell counts in the PK eyes to be lower due to the longer follow-up time, but the differential in cell density between the two groups (mean difference $50 \%$ ) is still greater than might be expected from time-dependent cell loss (mean PK follow-up 6.6 years, mean DLK follow-up 4 years).

Lamellar keratoplasty has been used in the management of corneal disease for many years. The problem of poor final visual acuity due to interface opacities has been largely overcome by the application of air injection to achieve deep lamellar dissection as described by Archila ${ }^{9}$ and others. ${ }^{10,11}$

Our surgical technique differed from that of Sugita and $K$ ondo ${ }^{1}$ in a number of respects. We used an initial air dissection, which can sometimes effectively cleave Descemet's membrane from the posterior stromal surface. If this does not occur then subsequent forceful hydrodissection into the deep stromal fibres can often achieve the same result. Once the pre-Descemet's plane is opened, viscoelastic can be injected into this space to hold Descemet's membrane clear whilst the final stromal fibres are resected with scissors. Air dissection must always be followed by paracentesis to allow escape of air that has refluxed through the trabecular meshwork into the anterior chamber. A low intraocular pressure can then be maintained by drainage through the paracentesis before Descemet's membrane is exposed, which reduces the risk of its rupture. Our series also differed in that we used pre-lathed lyophilised tissue in all cases, whereas Sugita and Kondo used fresh or frozen corneas in theirs. The patient groups were also different since they did not include any keratoconus patients, whereas keratoconus was the major indication in our series. The post-operative cell counts were particularly good in this group in our series, so this may well explain why the cell count for our whole patient group was better than that recorded by Sugita and Kondo.

DLK may be used as an alternative to PK where endothelial function is good. DLK has many advantages over PK. It eliminates the risk of endothelial rejection, which is the most common cause of graft failure following penetrating keratoplasty. It also allows reduction of the post-operative dose of corticosteroids, reducing morbidity from steroid-induced promotion of infection, and steroid-induced cataract and glaucoma. By using lyophilised tissue, immunological sensitisation of the recipient is avoided ${ }^{12}$ and therefore the risk of rejection for a subsequent penetrating graft, if it were to be required, is probably not increased.

\section{Conclusion}

The use of these surgical techniques appears compatible with retaining good host endothelial densities. Further studies including both pre- and post-operative endothelial assessment in patients with clear corneal stroma (e.g. keratoconus) would enable us to assess more accurately the surgically induced cell loss. Long-term follow-up of our patients will be necessary to see whether there is any progressive long-term cell loss as is seen in PK. However, since these patients are starting off with significantly higher cell counts than are commonly seen following PK, we expect a good long-term prognosis.

\section{References}

1. Sugita J, Kondo J. Deep lamellar keratoplasty with complete removal of pathological stroma for vision improvement. $\mathrm{Br}$ J Ophthalmol 1997;81:184-8.

2. Redmond RM, Armitage WJ, Whittle J, Moss SJ, Easty DL. Long-term survival of endothelium following transplantation of corneas stored by organ culture. $\mathrm{Br} \mathrm{J}$ Ophthalmol 1992;76:479-81.

3. Ing JJ, Ing $\mathrm{HH}$, Nelson LA, Hodge DO, Bourne WM. Endothelial cell loss ten years after penetrating keratoplasty. Invest Ophthalmol Vis Sci 1997;37:938.

4. Abbott R, Fine M, Guillet E. Long term changes in corneal endothelium following keratoplasty: a specular microscopic study. Ophthalmology 1983;90:676-85.

5. Zacks CM, Abbott RL, Fine M. Long-term changes in corneal endothelium after keratoplasty. Cornea 1990;9:92-7.

6. United Kingdom Transplant Support Service Authority. Cornea transplant audit 1990-1994. Bristol: UKTSSA, 1996. ISSN 1358-6564.

7. Bourne WM, Kaufman HE. Specular microscopy of human corneal endothelium in vivo. Am J Ophthalmol 1976;81:319-23.

8. Frueh BE, Böhnke M. Endothelial changes following refractive surgery. J Cataract Refract Surg 1996;22:490-6.

9. Archila EA. Deep lamellar keratoplasty dissection of host tissue with intrastromal air injection. Cornea 1984;3:217-8.

10. Chau GK, Dilly SA, Sheard CE, Rostron CK. Deep lamellar keratoplasty on air with lyophilised tissue. Br J Ophthalmol 1992;76:646-50.

11. Kirwan JF, Dalton R, Teimory M, Rostron CK. Deep lamellar keratoplasty: refractive results. Invest Ophthalmol Vis Sci 1996;37:S555.

12. Moore MB, Gebhardt BM, Verity SM, McDonald MB. Fate of lyophilized xenogenic corneal lenticules in intrastromal implantation and epikeratophakia. Invest Ophthalmol Vis Sci 1987;28:555-9. 